Reprinted from the Archives of Surgery

August, 1929, Vol. 19, pp. 321-326

\title{
VARIATIONS IN THE EXTRAHEPATIC BILIARY TRACT *
}

MEREDITH G. BEAVER, M.D.

Fellow in Surgery, The Mayo Foundation

ROCHESTER, MINN.

The frequent recourse to surgery for disturbances in the function of the extrahepatic biliary tract makes imperative exact knowledge not only of the normal distribution of the bile ducts but of the variations occasionally encountered in this system.

The literature contains frequent references to this fact, and many cases are reported of injuries to the biliary tract during operation on subjects in whom the arrangement of the bile ducts was atypical. Jacobson ${ }^{1}$ reported a case in which he severed the common bile duct during an operation for gallstones, because the cystic duct paralleled the hepatic duct for some distance. Many instances of similar accidents have been reported. Werelius ${ }^{2}$ and Ginsburg and Speese ${ }^{3}$ reported cases in which transection of the common duct had been caused entirely by an anomalous arrangement of the ducts. Stetten ${ }^{4}$ reported a case in which the hepatic duct was divided instead of the cystic duct because of the parallel arrangement of the two.

Ruge ${ }^{5}$ described the various forms of the biliary tract and classified them under three main types. The first type consisted solely of the normal angular mode of union of the cystic duct with the hepatic duct. The second type of anomaly included those in which the cystic duct paralleled, for a certain distance, the choledochus. The third type included the two arrangements of the cystic duct in which, instead of leading directly into the right side of the hepatic duct, it wound around it, either anteriorly or posteriorly. Eisendrath ${ }^{\circ}$ (1918 and 1920)

* Work done in the Department of Pathology, University of Oregon.

1. Jacobson, J. H.: Repair and Reconstruction of the Bile Ducts, Am. J. Obst. \& Gynec. 70:940, 1914.

2. Werelius, Axel: Accidental Surgical Injuries to the Bile Ducts with Report of a Case, J. A: M. A. 68:1545 (May 26) 1917.

3. Ginsburg, Nathaniel; and Speese, John: Autogenous Fascial Reconstruction of the Bile Duct, Ann. Surg. 65:79, 1917.

4. Stetten, De W.: Anomalous Relations of the Cystic Duct or Gallbladder to the Hepatic Duct, S. Clin. North America 3:539, 1923.

5. Ruge, Ernst: Beitrage zur chirurgischen Anatomie der grossen Gallenwege, Arch. f. klin. Chir. 87:47, 1908.

6. Eisendrath, D. N.: Anomalies of Bile Ducts and Blood Vessels as the Cause of Accidents in Biliary Surgery, J. A. M. A. 71:864 (Sept. 14) 1918; The Clinical Importance of Anatomical Anomalies in Biliary Surgery, Boston M. \& S. J. 182: 573, 1920. 
presented a study of 100 cases in which the variations in the biliary tract and their relations to the vascular system were discussed. $\mathrm{He}$ described each type of variation and specifically stated its significance in relation to accidents during operation. Flint ${ }^{7}$ described two cases, noted clinically, of variations in the distribution of the biliary tract. In one, an accessory cystic duct was encountered during operation for gallstones; in the other, in which operation for cholecystitis was carried out, the cystic duct paralleled the choledochus for its entire length and emptied directly and independently into the duodenum. In an embryologic and comparative study of aberrant biliary vesicles in man and other mammals, Boyden ${ }^{8}$ presented valuable data concerning the frequency with which duplication of the gallbladder may be encountered. In studies on 10,000 domestic animals and reports on 19,000 cadavers and patients in hospitals, the incidence varies somewhat as follows: once in 8 cats; once in 28 calves; once in 85 sheep; once in 198 pigs, and once in from 3,000 to 4,000 human beings. Accordingly, such duplication of the biliary vesicle appears to be relatively rare in man.

A variation from the usual distribution of the biliary ducts, however, is common. Therefore, since cholecystectony is now more common than simple drainage of the gallbladder, a clear understanding of the more common variations in the distribution of the bile ducts is imperative.

\section{DATA OBTAINED DURING DISSECTION OF CADAVERS}

In this report, I wish to present the data which were accumulated during careful dissections of fifty-seven cadavers. The material for these dissections was obtained from necropsies performed for the coroner in Portland, Oregon, and the study was made in the laboratories of the Department of Pathology, the University of Oregon Medical School.

The extrahepatic tracts of the fifty-seven subjects which came under my observation in this study fall into four rather distinct groups. I was able to demonstrate the three types of distribution as described by Ruge and in general to confirm his observations as to the frequency of these variations. The first group of cases, those in which the angular mode of union maintains between the cystic and hepatic ducts constituted 58 per cent of all the dissections (fig. $1 a$ ).

I have subdivided Ruge's second group of variations, those in which the cystic duct coursed parallel to the common bile duct, by arbitrarily

7. Flint, E. R.: Gallstones Associated with Anomaly or Injury of Bile Ducts, Brit. M. J. 1:995, 1924.

8. Boyden, E. A.: The Accessory Gallbladder; an Embryological and Comparative Study of Aberrant Biliary Vesicles Occurring in Man and the Domestic Mammals, Am. J. Anat. 38:177, 1926. 
classifying the cystic ducts into two groups on the basis of their length. Furthermore, although the two ducts concerned are bound together in a fibrous union, their lumens are separate. Therefore, it seens better to speak of the cystic duct as running parallel to the hepatic duct and not to the common duct. I have designated the cystic ducts which

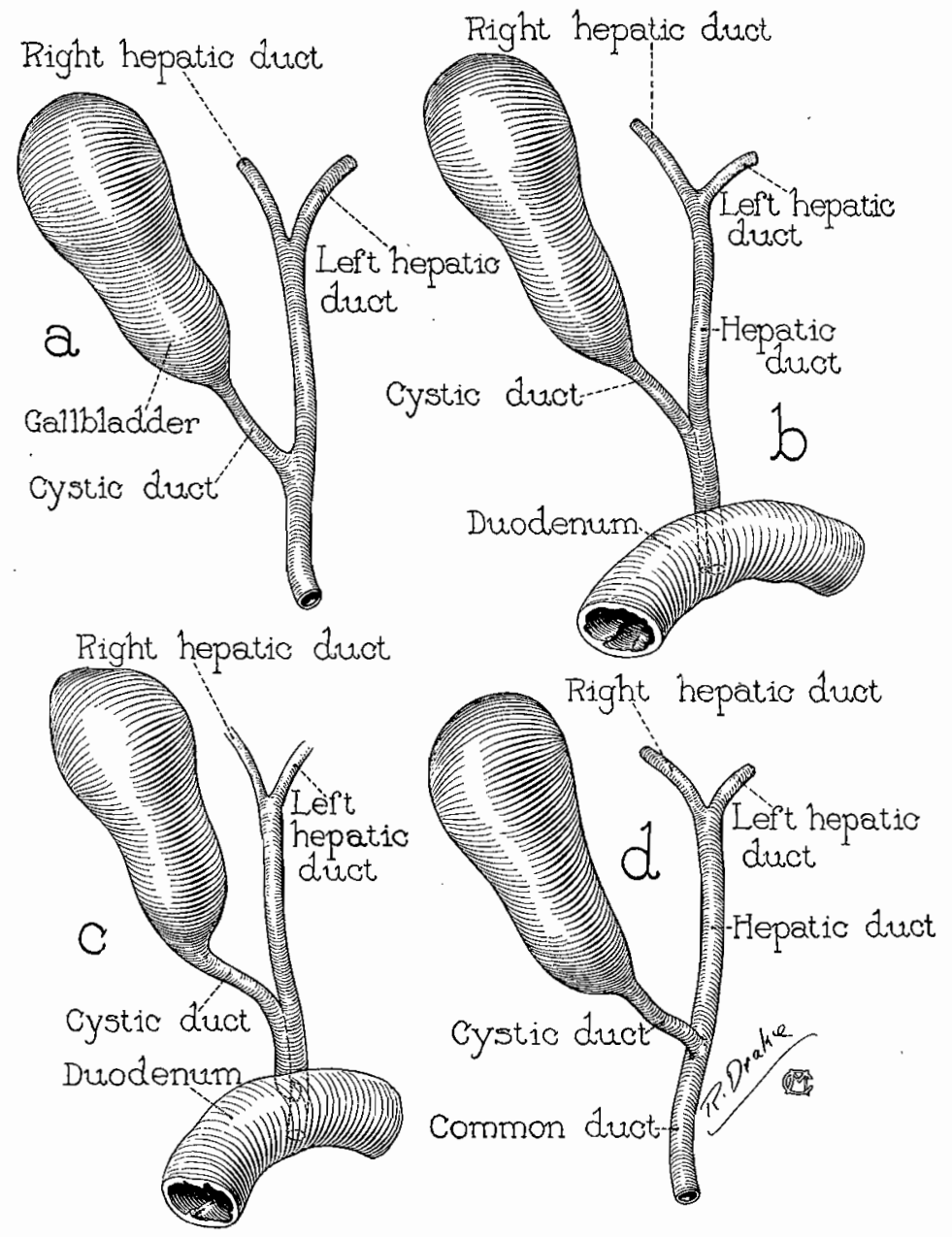

Fig. 1.-Mode of union of cystic and hepatic ducts: $a$, normal angular; $b$, long parallel; $c$, short parallel, and $d$, anterior spiral.

follow the hepatic bile duct as far as the upper border of the duodenum, as the short parallel type (fig. $1 \mathrm{c}$ ), and I have designated the ducts which extend farther, to within $1 \mathrm{~cm}$. of the ampulla of Vater, as the long parallel type (fig. $1 \mathrm{~b}$ ). In both of these types, however, the cystic and the hepatic ducts are bound together so intimately by fibrous connective tissue that it is almost impossible to separate them. In this 
series, 26.3 per cent of the ducts were of the short parallel type and 7 per cent were of the long parallel type. The delayed juncture of the cystic and hepatic ducts, as in these variations, results in a greatly lengthened cystic duct and a relatively short common bile duct. In these aberrant cystic ducts, however, the valves were restricted to the

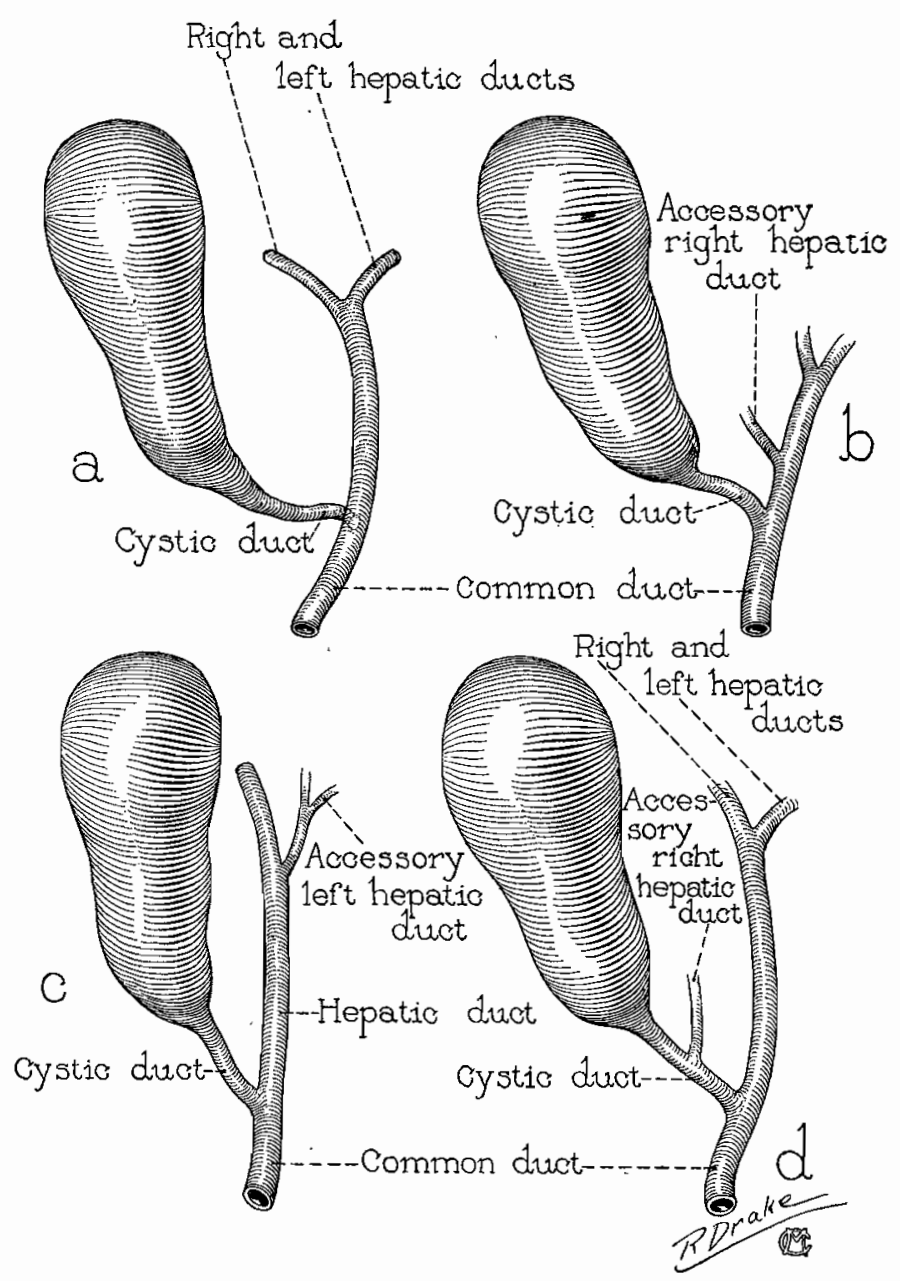

Fig. 2.-a, posterior, spiral mode of union of cystic and hepatic ducts; $b$, accessory right hepatic duct; $c$, accessory left hepatic duct, and $d$, accessory right hepatic duct emptying into the cystic duct.

normal site, for the remaining portion parallel to the hepatic duct was invariably patent throughout.

Of all the cases that came under niy observation, 12.3 per cent could be placed in Ruge's third group, the group which includes the anterior and the posterior cystic ducts. In these variations the cystic 
duct passes either anteriorly or posteriorly around the hepatic duct, describing from a quarter to a full turn around it. In my series, 7 per cent of the cases were of this anterior spiral variation (fig. $1 d$ ) and 5.3 per cent were of the posterior spiral type (fig. $2 a$ ).

To these three main types of anomalies, I have added a fourth, which includes variations in the distribution of accessory clucts. The first of these is an accessory hepatic duct which courses from the liver at the extreme right of the portal fissure and empties into the extrahepatic biliary tract anywhere between the point of confluence of the right and left hepatic ducts and the orifice of the cystic duct (fig. $2 \mathrm{~b}$ ). This particular type of accessory hepatic duct has been hitherto described, but these accessory ducts have been found in the right side of the liver only. In my series a second accessory variation was occasionally encountered (fig. $2 \mathrm{c}$ ). This duct leaves the liver at the left of the portal fissure and empties into the left hepatic duct before the latter joins the right hepatic duct to form the main hepatic bile duct. As far as I have been able to determine, this left accessory hepatic duct has never been described before. Accessory hepatic ducts, both right and left, were encountered in 3.5 per cent of all subjects examined.

Furthermore, an additional type of accessory duct was encountered in 5.3 per cent of all cases. This duct leaves the liver on the right side of the portal fissure and enters into the cystic duct, instead of into the hepatic duct, just above the confluence of the cystic duct with the hepatic duct (fig. $2 d$ ).

\section{SLMMARY AND CONCLUSIONS}

1. The normal angular mode of juncture of the cystic duct with the hepatic duct, as described in textbooks of anatomy, occurred in only a little more than half of the cases ( 58 per cent).

2. The long and short parallel types of cystic duct occur in more than a third of the cases and, as is shown by the literature, is perhaps the most common cause of accidents in biliary surgery. In such cases, there is a marked increase in the length of the cystic duct and a corresponding decrease in that of the common bile duct. The cystic duct and the hepatic duct are so intimately bound together by fibrous tissue that they are absolutely inseparable and thus appear as a single duct; any rough manipulation may tear the thin septum which exists between them. The large portion of a cystic duct of this type which remains following cholecystectomy may clilate and form a new gallbladder, probably with recurrence of symptoms. The cystic duct does not contain valves of Heister in the portion which lies parallel to the hepatic duct. The short parallel type occurred in 26.3 per cent of the cases in this series and the long parallel type in 7 per cent. 
3. The anterior and posterior spiral varieties comprised 12 per cent of this series. The length in the anterior spiral variety conforms closely to the normal; in the posterior spiral variety the cystic duct is markedly lengthened, and the hepatic and common ducts remain about normal. It has been recorded that strong traction on the gallbladder is much more likely to tear off a spiral cystic duct than a duct with a normal arrangement.

4. Accessory hepatic ducts occurred in five cases, or 8.7 per cent of this series. Four of these were accessory right hepatic ducts, three of which were also accessory to the cystic duct. In one case there was an accessory left hepatic duct. The length and diameter of the dccessory ducts corresponded closely to the normal cystic duct. 